\title{
Design and Techno-Economical Optimization of Wind Turbine Generator System: Under Diverse Metrological Conditions
}

\author{
Marangi S. Mbogho, ${ }^{1, *}$ and Michael J. Saulo \\ ${ }^{1}$ Faculty of Engineering and Technology, Technical University of Mombasa, Kenya \\ ${ }^{2}$ Department of Electrical and Electronics Engineering, Kenya
}

\begin{abstract}
The Kenyan Electricity Supply Industry (KESI) generation mix comprises; hydro-electric, geothermal, thermal and a small contribution from wind energy. Over the years, the predominant source of electricity generation in KESI has been hydro (over 60\%). However, due to climate changes in recent times hydro generation has become less reliable and largely contributed to the supply-demand mismatch. Against this background there has been a paradigm shift in energy policy towards the use of Renewable Energy sources for electricity generation. Informed by this shift of policy, this paper explores the possibility of generating electrical power from wind-at Mokowe, Lamu County, in Kenya along the Indian Ocean. The paper contends that the use of optimally designed Wind Turbine Generators (WTGs) could enhance production of electrical power at the proposed site. This in effect would significantly: improve the technical and economic performance of KESI; and impact positively on the socio-economic status of the local communities at Makowe.
\end{abstract}

Keywords: Techno-economical optimization, Wind turbine generator, Renewable energy optimal sizing, competing incentive, green economy.

\section{INTRODUCTION}

Kinetic energy of wind intercepted by wind turbine generator blades per minute depends on: the air density, area swept by rotor blades, and the cube of wind speed regulated by efficiency or power factor of the wind generator [1].

This paper presents a techno-economical optimization study of a proposed stand-alone/grid connected wind turbine generator system at Mokowe, in Lamu County, Kenya. The main objective of the paper is to integrate the diverse meteorological conditions (wind speeds) in Lamu proportionately to the designed wind turbine generators (WTG). This is done to optimize sizing between maximum power generated by each type of turbine and the competing incentive to maximize the number of generator turbines sited per unit area. The study uses historical/pseudo meteorological wind data to develop a complete sizing model that provides an optimum system configuration on the basis of techno-economical optimization.

\section{BACKGROUND}

In the recent years, there has been a rapid increase in the amount of wind-generated power on electrical power grids worldwide. Subsequently, the inclusion of accurate models of wind turbine generators (WTGs) in power system analysis software is important. Steady-

*Address correspondence to this author at the Faculty of Engineering and Technology, Technical University of Mombasa, Kenya;

E-mail: marangimbogho@gmail.com state and dynamic models of wind turbine generators are required for different types of simulation studies. Steady state fixed speed and variable speed models are both necessary for different applications. In this paper the dynamic models are considered in terms of their effect on the power flow convergence and voltage stability limit [4].

Currently, Kenya's installed power capacity is about $1089 \mathrm{MW}$ with maximum power demand of $1300 \mathrm{MW}$ [2]. This demand/supply mismatch has been the source of persistent power supply interruptions. Moreover, with an estimated $17 \%$ loss in electricity generated through transmission lines, against a global best practice of below $12 \%$, this scenario does not augur well for the country's future electricity supply-demand prospects. One of the prerequisites for the realization of Kenya's Vision 2030 is reliability in electricity supply. Therefore, the country has to make concerted efforts to expand its electrical power production in order to meet the expected increase in electricity supply for sustainable industrialization to take place [3]. The proposed Mokowe wind farm with connection to the grid is shown in Figure 1.

\section{STOCHASTIC WIND SPEED SIMULATION}

Generating realistic wind speeds is an important task when effects of wind productions in an electricity supply system have to be analysed. The fluctuating wind speed is the origin of the temporal variation of the electrical power injected and thus has direct effect on electricity supply system stability. One of the challenges of wind speed simulators is mainly to 


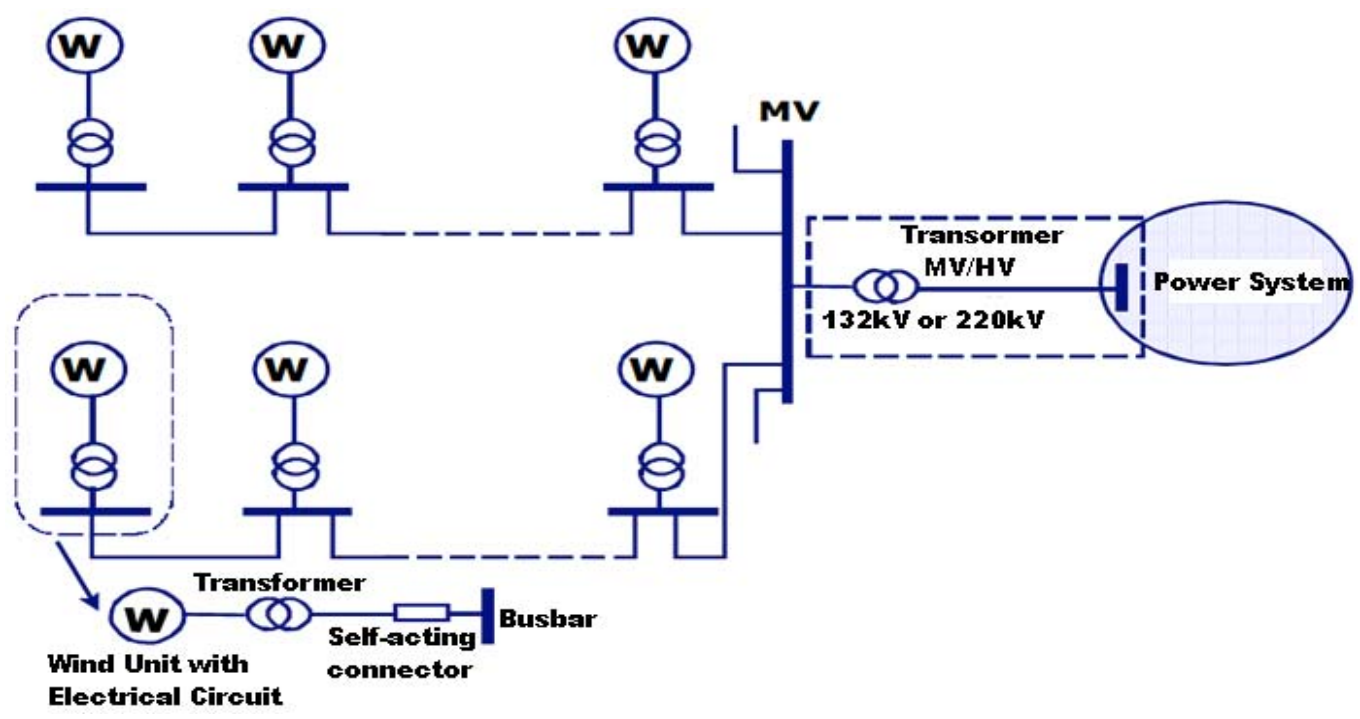

Figure 1: Proposed Wind farm at Mokowe site. Source: [4].

reproduce the different scale fluctuations. While fixed speed generators are simpler, cheaper and have low maintenance requirements, variable speed systems allow the control of active and reactive power within specified margin. They are capable of reducing the dynamic stress on the mechanical parts and can minimize power oscillations producing flicker [4].

In this paper the dynamic behaviour of a doubly fed induction generator when connected to the grid is studied. The study consists of two stages, a slow and fast component as described in successive sections. With some minor modification, more accurate wind models (that take into consideration long-term [6] or cross-correlations [7]) are of this nature. An overview of some more approaches are found in [8]. It is important to add that, to get a realistic simulation of a specific site, records of historical data are needed to obtain the parameters of the model, because even the best model is useless if not accurately fitted.

\subsection{The Slow Component}

The slow component is a time series model based on an ARMA (Automatic Regressive Moving-Average) model that is given by [5].

$y_{t}=\phi_{1} y_{t-1}+\phi_{2} y_{t-2}+\ldots+\phi_{n} y_{t-n}+\alpha_{t}$

$+\theta \alpha_{t-1}+\theta_{2} \alpha_{t-2}+\ldots \theta_{m} \alpha_{t-m}$

The first part, which was already used by author [9], is a generator of hourly mean wind speeds. The data series $y_{t}$ is used to build the model, that is to calculate the auto-regressive $\varnothing_{i}, i=1,2 \ldots, n$ and the moving average parameters $\varnothing_{i}, j=1,2 \ldots, m\left\{\alpha_{t}\right\}$ is a Gaussian white noise process with zero mean and standard deviation of $\sigma_{a}$ that is part of the moving average (MA) of the model. Considering the orders, the process is referred to as ARMA $(n, m)$. The parameter used in this paper were chosen from an ARMA $(3,2)$ approach, but the model was developed up to $(4,3)$ and can be easily adapted to other orders. For example, a pure AR (2) model [8] which was implemented before can also be seen as an ARMA model with $n=2$ and $m=0$. The order of the model depends on the quantity of historical data available, because if there is only a little data, an accurate model cannot be reached even with higher orders. There is a range of literature available regarding parameter estimation. Fitting models are normally based on least square regression methods that try to minimise the error value. For AR parameter estimation, the Yule-Wallker equations are widely used. The simulated hourly mean wind speed [6] are obtained as

$\overline{v_{1}}(t)=\mu+y_{t}$

Where $\mu$ is the mean wind speed of all the observed data. If observed hourly mean speeds $\mu_{h}$ and standard deviation oh are available, a more realistic simulated wind speed is calculated as

$\overline{v_{2}}(t)=\mu_{h}+\sigma_{h} \cdot y_{t}$

This method is explained in detail in [6].

\subsection{The Fast Component}

The ability to compute hourly mean wind speeds might be enough for several applications of the energy 
systems model, but as temporal scalability is a requirement for the latter, a more detailed model is needed. However, the ability to reproduce realistic wind speeds in real time, may be achieved by adding the so called fast component to the previously described slowly varying signal. For this purpose turbulent phenomena are modelled by a highly fluctuating signal given in [5] by the following differential equation.

$\frac{d \omega}{d t}=-\frac{\omega(t)}{T}+k v_{h}(t) \sqrt{\frac{2}{T}} \xi(t)$

Where $T=L / \bar{v}, \mathrm{~L}$ being the turbulence length scale, $v$ is the velocity of wind, $\mathrm{k}$ a factor that depends on the geographical location of the wind turbine site [9], $\xi(t)$ a Gaussian white noise and $v_{h}(t)$ the hourly mean wind speed. Equation (4) describes a stationary Gaussian process that allows us to generate a time continuous signal that represents area time wind speed.

\section{TURBINE MODELING}

There are several technical models for wind turbines. The model used in this paper is a generic approach that considers the agent-based approach of the framework. Since the wind turbine need to be replicated (in order to create wind farms with tens or even more turbines), a simple model may be chosen to ensure fluid simulations. The basis of this model is the relation between the power output of the turbine that is a function of the wind speed actuating on its rotor blades. Three different models that are commonly used have been identified in the course of this study. The real model is not a mathematical model itself. It just shows the $P(\mathrm{v})$ curve of a specific turbine-based on the manufacturers' data. In general, the curve has a shape similar to the one shown in Figure 2 [10].

Figure 2, shows a typical power-wind speed profile of a wind turbine. The cut-in speed defines the minimum wind speed at which the turbine can start working; the nominal wind speed is the point at which rated power is achieved. Nominal power is almost constant up until the cut off wind speed is reached, at which point the turbine must be shut down to avoid damage caused by strong winds. In this regard, four principle states are defined as [9, 10];

- $\quad$ Stopped : for $v \leq v_{\text {cut-in }}$

- $\quad$ Partial load : for $v_{\text {cut-in }} \leq v \geq v_{\text {norm }}$

- $\quad$ Rated load : $v_{\text {norm }} \leq v \geq v_{\text {cut-off }}$

- $\quad$ Cut-off : $v \geq v_{\text {cut-off }}$

The transitions between the states are smooth because of the technical characteristics of the rotor and generator in the real curve. The most interesting state to be observed is the partial loaded state, where the turbine shows a non-linear $P(v)$ dependence. In this phase, the dynamic of the turbine as well as the adoption to the fully loaded capacity at rated speed is observed. This phase is approximated by a polynomial term shown in Figure 3.

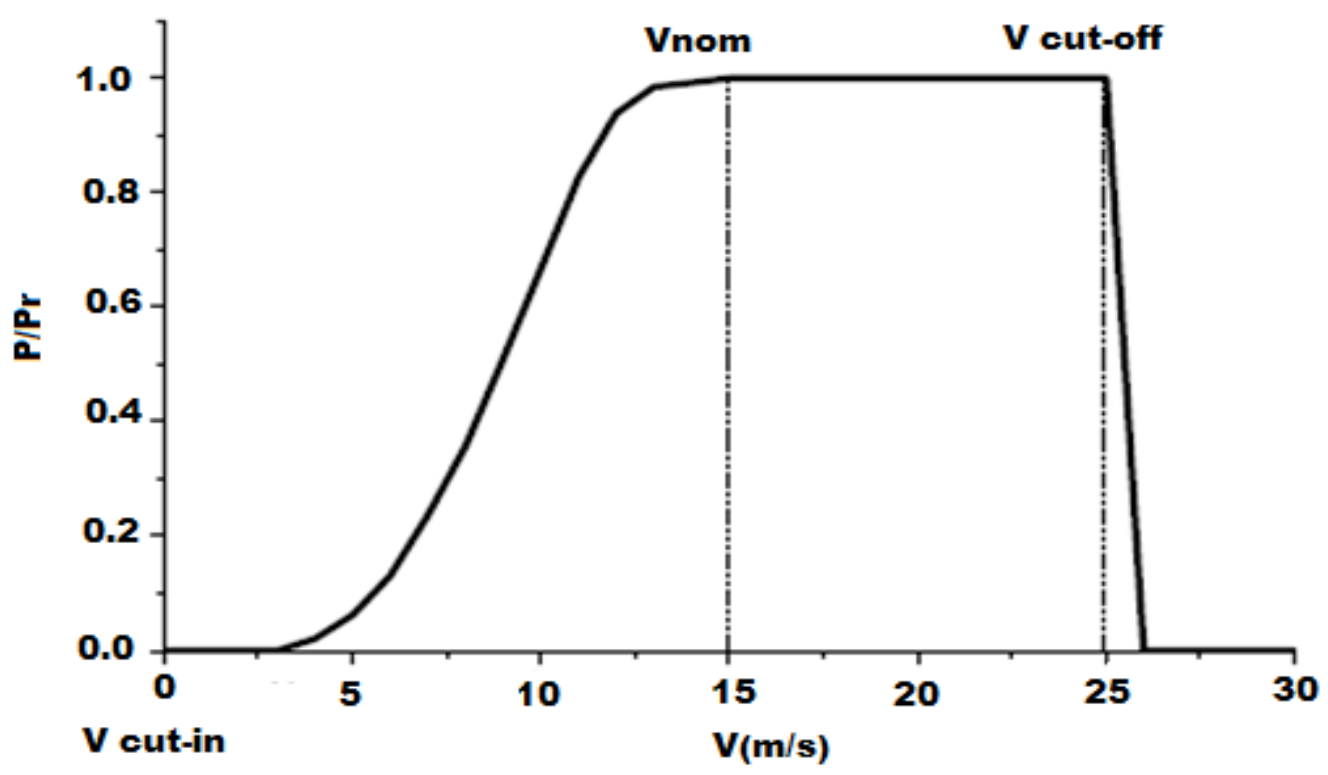

Figure 2: A simple power curve. Pr is the rated power. Source: [10]. 


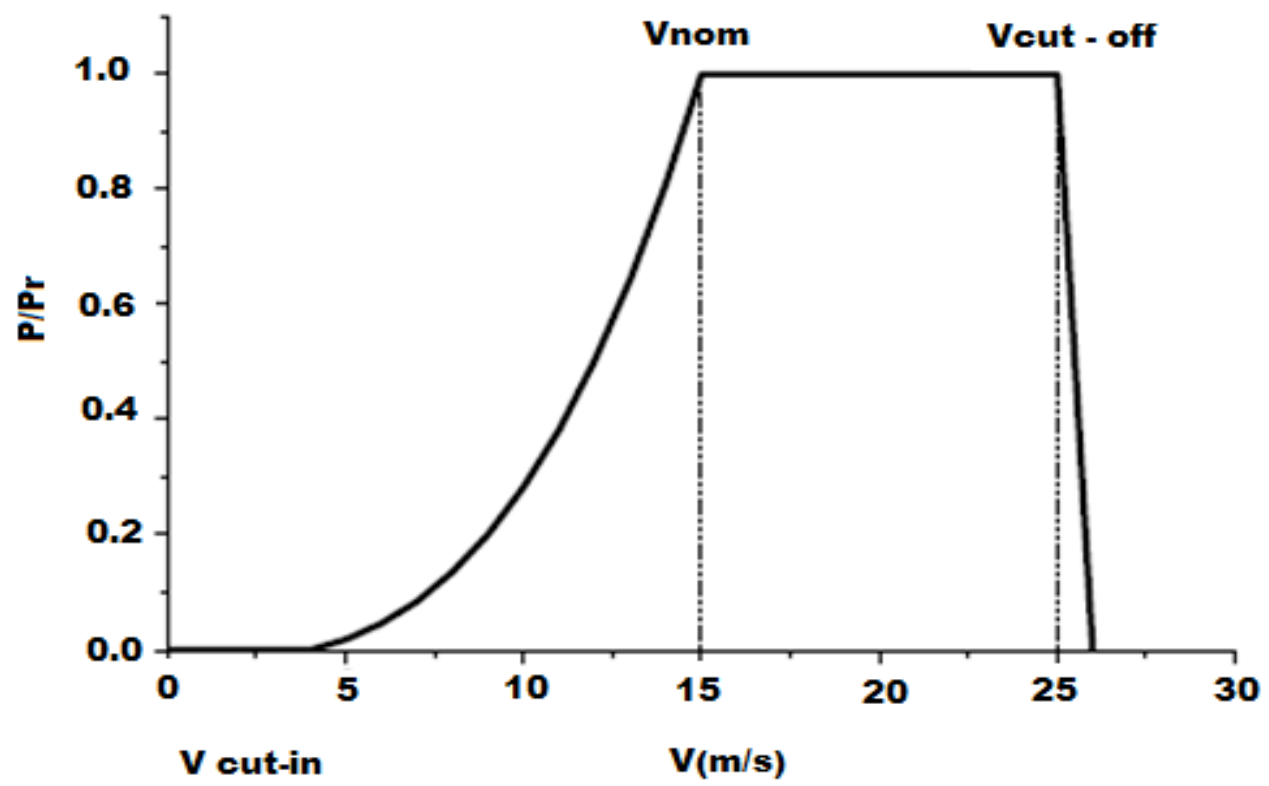

Figure 3: Polynomial approximated power curve. Source: [11].

The polynomial model generates the curved part of the curve, but the trace just before achieving the nominal wind speed is idealised. The linear approximation of the curve which is used in more simplified models, is defined by linear interpolation of the values for $v_{\text {cut }-i n}$ and $v_{\text {norm }}$. This is as shown in Figure 4. The last model might be useful when only the characteristics wind speeds of the turbine (and no power curve) are available. Though, the polynomial approach can also be used as approximation by using a polynomial of degree three as described in [11].

The cut-off state is attained when the turbine shutsdown because of exceeding the parameter $v_{\text {cut-off }}$. Further, the parameter $v_{\text {cut-back-in }}$ is defined for the model. The value of $v_{\text {cut-back-in }}$ denotes the wind speed, at which the turbine gets back to work after having entered the cut-off state. This value adds the restart behaviour of the machines after strong wind period.

\subsection{System Modelling}

The power extraction from wind turbine comprise three main factors: wind power available, the power curve of the machine and the ability of the machine to respond to wind fluctuation. The expression for power produced by the wind is given by $[12,13]$ :

$$
P_{m}(v)=\frac{1}{2} C_{P}(\lambda, \beta) \rho \pi R^{2} v^{3}
$$

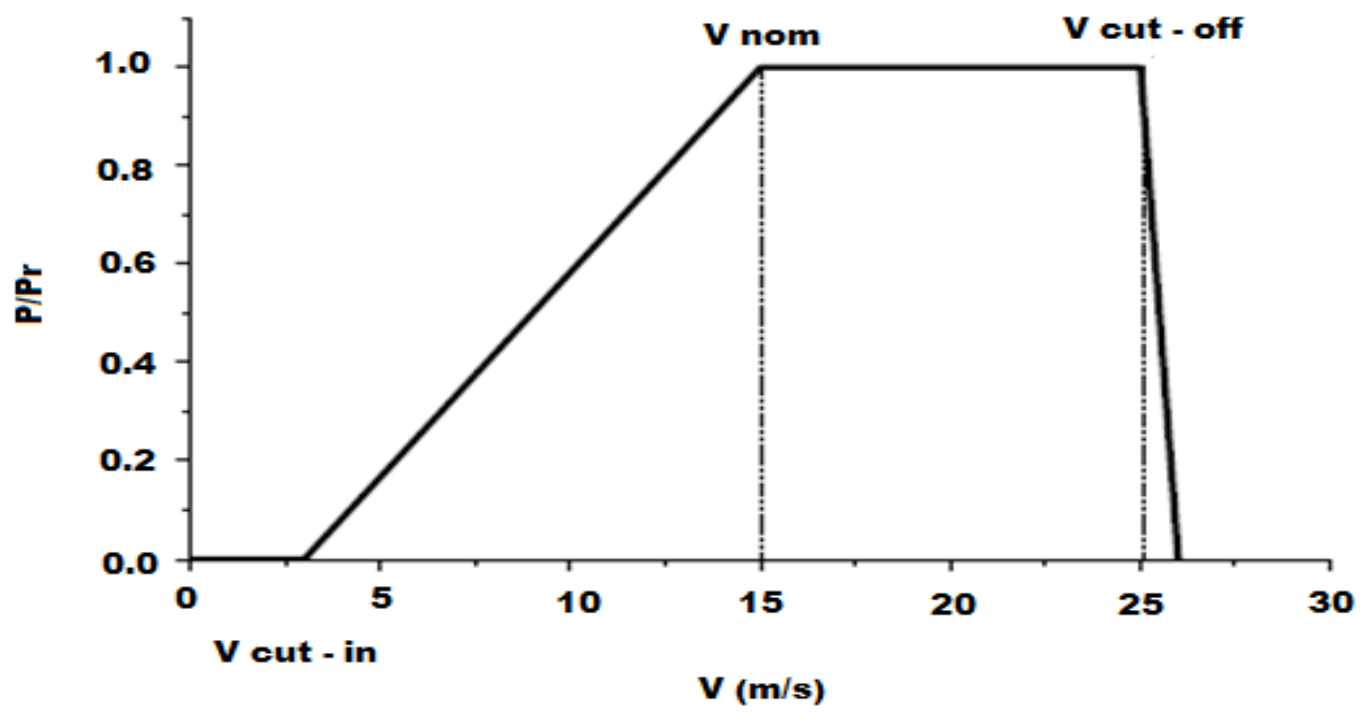

Figure 4: Linear simplified power curve. Source: [11]. 
Where $\rho$ is the air density $R$ is radius of turbine rotor, $v$ is wind speed, $C_{p}$ is power coefficient of wind turbine, $\lambda$ is the tip speed ratio and $\beta$ represents pitch angle. The tip-speed ratio is defined as:

$\lambda=\frac{R \omega}{v}$

Where $\omega$ is the turbine rotor speed. Therefore, if the rotor speed is kept constant, then any change in the wind speed will change the tip speed ratio, leading to change of power coefficient $C_{p}$, as well as the generated power output of the wind turbine. However, if the rotor speed is adjusted according to the wind speed variation, then the tip-speed ratio can be maintained at an optimal point, thereby yielding maximum power output from the system.

For a typical wind electricity generation system, the following simplified elements are used to illustrate the fundamental working principle. The system primarily consists of an aero turbine, which converts wind energy into mechanical energy, a gearbox that serves to increase the speed and decrease the torque and a generator that convert the mechanical energy into electrical energy.

The mechanical equation is characterized by [14]:

$J_{m} \omega+B_{m} \omega=T_{m}+T$

$J_{e} \omega_{e}+B_{e} \omega_{e}=T_{t}+T_{e}$

$T_{t} \omega_{e}=-T \omega$

Where $J_{m}$ and $J_{e}$ are the moment of inertia of the turbine and the generator respectively, $B_{m}$ and $B_{e}$ are the viscous friction coefficient of the turbine and the generator, $T_{m}$ is the wind generated torque in the turbine, $\mathrm{T}$ is the torque in the transmission shaft before gear box, $T_{e}$ is the generator torque, $\omega$ is the angular velocity of the turbine shaft and $\omega_{e}$ is the angular velocity of the generator rotor.

The relationship between the angular velocity of the turbine $\omega$ and the angular velocity of the generator $\omega_{e}$ is given by the gear ratio:

$Y=\frac{\omega_{e}}{\omega}$

Then, using Equations 7, 8, 9 and 10 we obtain

$J_{\omega}+B_{\omega}=T_{m}-Y T_{e}$
With

$$
\begin{aligned}
& J=J_{m}+Y^{2} J_{e} \\
& B=B_{m}+Y^{2} B_{e}
\end{aligned}
$$

From Equations 5 and 6 we deduce that the input wind torque is:

$T_{m}(v)=\frac{P_{m}(v)}{\omega}=\frac{P_{m}(v)}{\frac{\lambda v}{R}}=k_{v} v^{2}$

Where

$k_{v}=\frac{1}{2} C_{P} \rho \pi \frac{R^{3}}{\lambda}$

Now let us consider the systems electrical equations. In this study we used a double feed induction generator (DFIG) whose characteristic matches the metrological conditions in Mokowe. The induction machine is feed from both stator and rotor. The stator is directly connected to the grid or a standalone medium voltage distribution line, while the rotor is fed through a variable frequency converter (VFC).

In order to inject electrical power at constant voltage and frequency to the utility grid, over a wide range (from subsychronous to super synchronous speed), the active power flow between the rotor circuit and the grid must be controlled both in magnitude and in direction. Therefore, the VFC consist of two four-quadrant insulated gate bipolar transistor pulse width modulator IGBT PWM converters; Rotor side converter (RSC) and grid side converters (GSC) connected back to back by a dc link capacitor $[15,16]$.

\subsection{Doubly Fed Induction Generator (DFIG) Control Scheme}

In order to extract the maximum active electrical power from the wind, the shaft speed of the Wind Turbine Generator (WTG) must be adjusted to achieve an optimal tip-speed ratio $\left(\lambda_{\text {opt }}\right)$ which yields the maximum power coefficient $\left(C_{p \max }\right)$ and therefore maximum power [17]. In other words, given a particular wind speed, there is a unique wind turbine speed required to achieve the goal of maximum wind power extraction. The value of $\lambda_{\text {opt }}$ which can be determined from the maximum of the power coefficient curves versus tip speed ratio depends on the turbine modeling characteristics. The power coefficient $C_{p}$, is 
approximated by Equation (16) based on the modeling turbine characteristics [18].

$C_{P}(\lambda, \beta)=C_{1}\left(\frac{C_{2}}{\lambda_{i}}-C_{3} \beta-C_{4}\right) e^{\frac{-C_{5}}{\lambda_{i}}}+C_{6} \lambda$

Where the coefficients $\mathrm{C}_{1}$ to $\mathrm{C}_{6}$ depends on the wind turbine design characteristics and $\lambda_{i}$ is defined as

$\frac{1}{\lambda_{i}}=\frac{1}{\lambda+0.08 \beta}-\frac{0.035}{\beta^{3}+1}$

The value of $\lambda_{\text {opt }}$ can be calculated from the roots of the derivatives of Equation (16). Then, based on the wind speed, the corresponding optimal wind turbine speed reference $\omega^{*}$ for maximum wind power tracking is determined by:

$\omega^{*}=\frac{\lambda_{o p t} \cdot v}{R}$

The DFIG wind turbine control system generally consists of two parts: the electrical control and mechanical control on the wind turbine blade pitch angle. Control of DFIG is achieved by controlling the VFC that includes control of RSC and control of the GSC [19]. The objective of the RSC is to govern both the stator side active and reactive power independently. Whereas the objective of the GSC is to keep the dc-link voltage constant regardless of the magnitude of the direction of the rotor power. The GSC control scheme can also be designed to regulate the reactive power or the stator terminal voltage of the DFIG.

A typical scheme of a DFIG equipped wind turbine is shown in Figure 5 [10].
The RSC control scheme is designed in order to regulate the wind turbine speed for maximum wind power capture. Therefore, a suitably designed speed controller is essential to track the optimal wind turbine speed reference $\omega^{*}$ for maximum wind power extraction.

These objectives are commonly achieved by electrical generator rotor current regulation on the stator-flux oriented reference frame [20]

\section{SIMULATION METHODOLOGY}

The simulations were carried out using the Matlab/Simulink software and the turbine SimPowerSystems library [21]. The objective of these simulations was to study the variable speed wind turbine regulation performance using a sliding-mode field oriented control scheme. This was done to maximize the wind power extraction in order to obtain the maximum electrical power. In this regard, the wind turbine speed was to be adjusted continuously against wind speed.

The proposed variable speed wind farm had a rated power capacity of $9 \mathrm{MW}$. The farm consisted of six 1.5 MW turbines connected to a $415 \mathrm{~V}$ bus line. The wind turbine used a doubly- fed induction generator (DFIG) consisting of a wound rotor induction generator and an AC/DC/AC, IGBT-based PWM converter. The stator winding was connected directly to the $50 \mathrm{~Hz}$ grid while the rotor was fed at variable frequency through the $\mathrm{AC} / \mathrm{DC} / \mathrm{AC}$ converter.

The system had the following mechanical parameters. The combined generator and turbine inertia constant is $\mathrm{J}=5.04 \mathrm{~s}$, the combined viscous

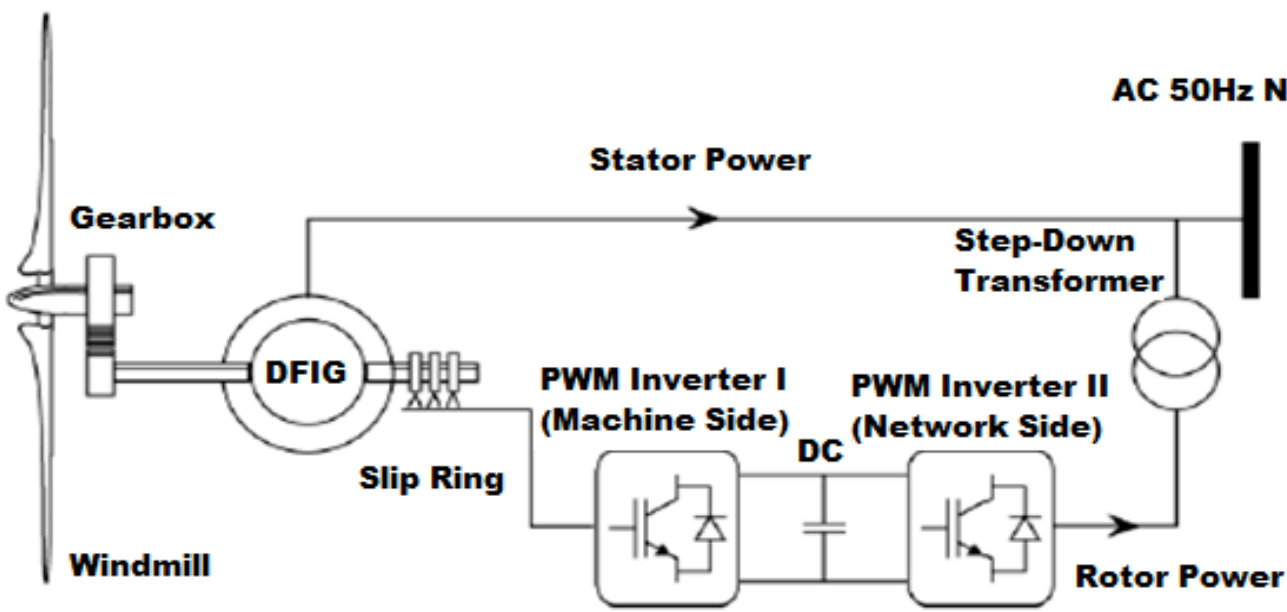

Figure 5: DFIG equipped wind turbine scheme. Source: [10]. 


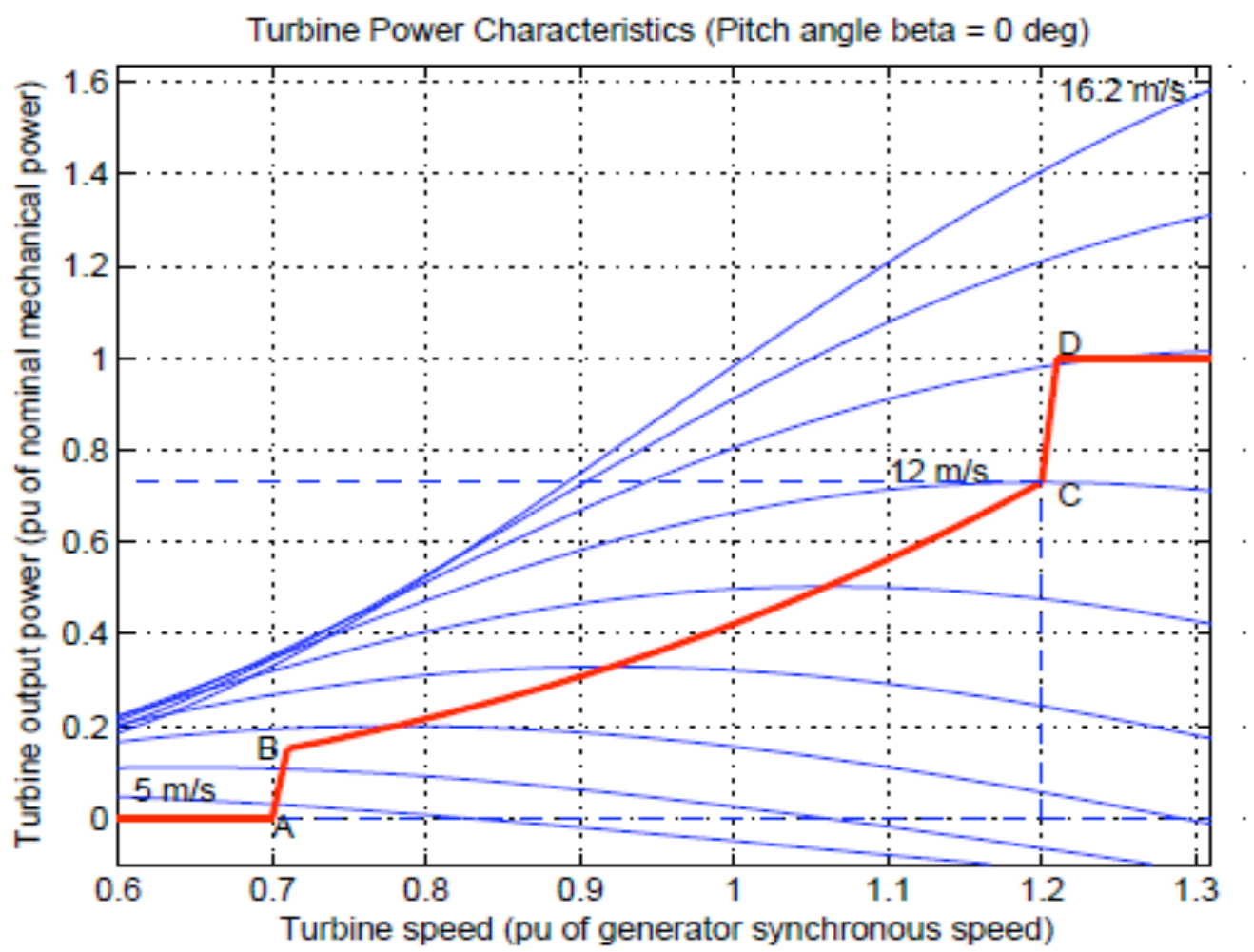

Figure 6: Turbine power Characteristics. Source: [15].

friction factor $\mathrm{B}=0.01 \mathrm{pu}$ based on the generator rating and there were three pole pair [20]. In this simulation it was assumed that there is an uncertainty of about $20 \%$ in the system parameters which was overcome by the proposed sliding control. Finally, the following values were chosen for the controller parameters, $k=100$, $\beta=30$.

In this paper, the rotor was running at sub synchronous speed for wind speeds lower than $10 \mathrm{~m} / \mathrm{s}$ and running at a super-synchronous speed for higher wind speeds. Figure 6 displays the chosen turbine mechanical power characteristics as a function of turbine speed for speeds ranging from $5 \mathrm{~m} / \mathrm{s}$ to $16.2 \mathrm{~m} / \mathrm{s}$.

The simulation used an approximate variable wind speeds. Figures 7 and 8 shows the average wind speed and the pseudo hourly wind speed used for simulation respectively.

\section{RESULTS AND DISCUSSION}

Two main classes of models are dominant for wind speed forecasting; time series models and models based on metrological information. Time series models use past values of the process to predict its future. They are built for horizon ranging from a few seconds ahead (for automatic control) to a few hours ahead (for operational planning). Metrological models aim to cover longer horizon up to 48hours ahead (such are the models presented here). For a medium or large isolated system, where there are both fast and slow components the unit commitments function needs forecast up to 2 days ahead. Accurate forecasts in short term (up to 8 hours) are necessary for scheduling of the fast units. In this range, time-series models are expected to provide better results. It was observed that longer horizon models that take into account metrological information to be more beneficial.

The results presented in this paper on the load and wind speed optimization problem, show that improvements on the design of the system is based on performance of the model per day of the week (for load).

The model was run using wind speeds in Figure 8 that was derived from Figure 7. The wind speed data are measurements from Mokowe, Lamu County in Kenya. This is located in the coastal part of Kenya.

The wind data was converted to the projected power output using power curve of an ENERCON-40 $(500 \mathrm{~kW})$ machine shown in Figure 6. A number of runs were carried out using different numbers of installed wind turbines representing penetration level of wind powers from $0 \%$ up to $5 \%$ of the current installed capacity. 


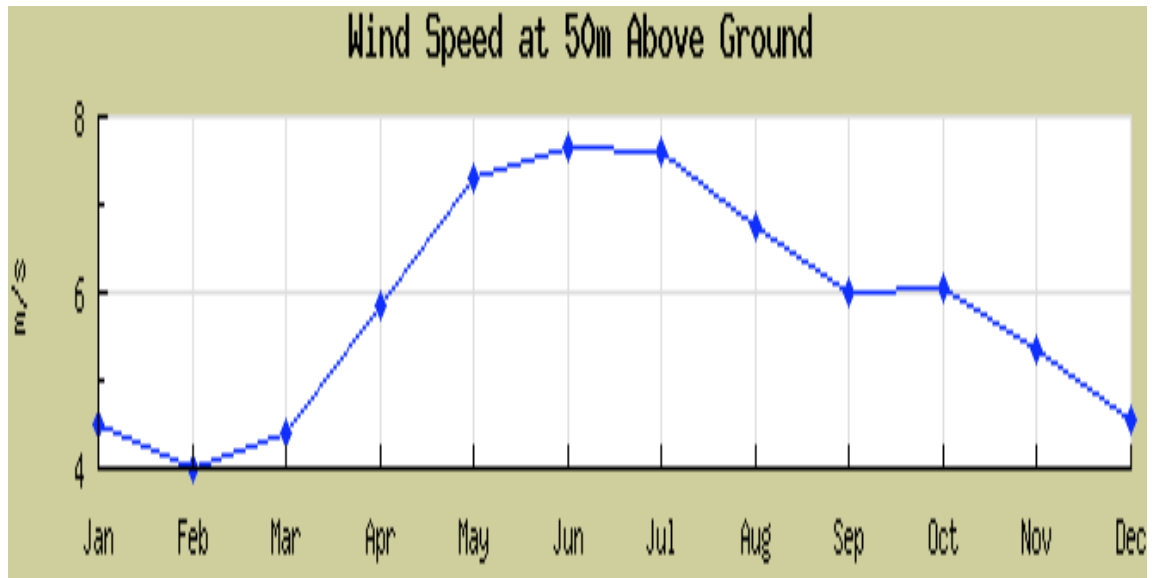

Figure 7: Average wind speed at 50m above ground in Mokowe-Lamu. Source: SWERA.

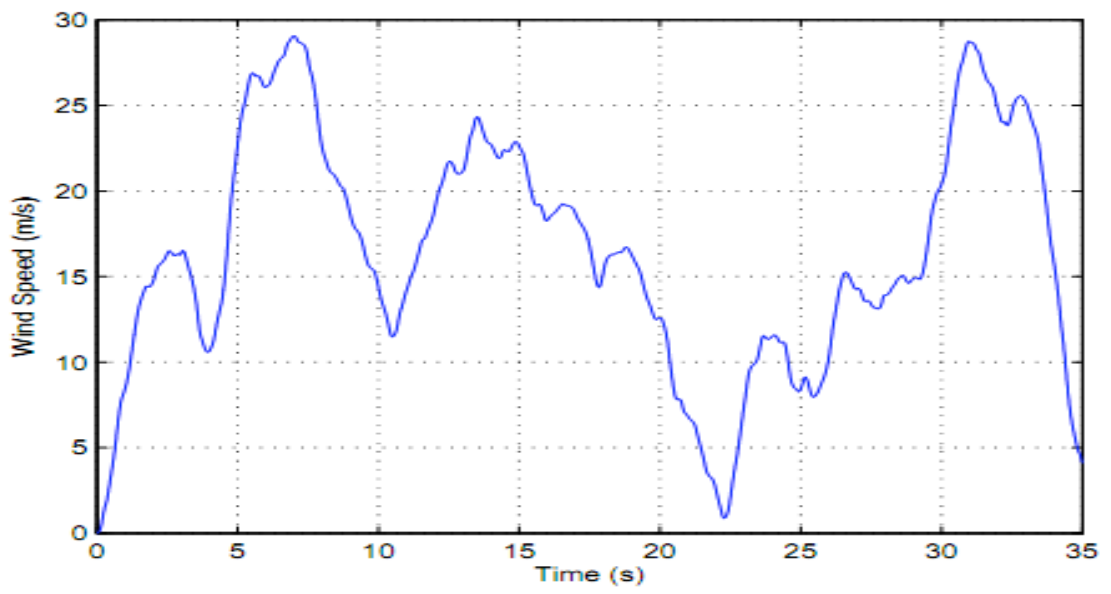

Figure 8: Wind Speeds (Source: Generated by the study).

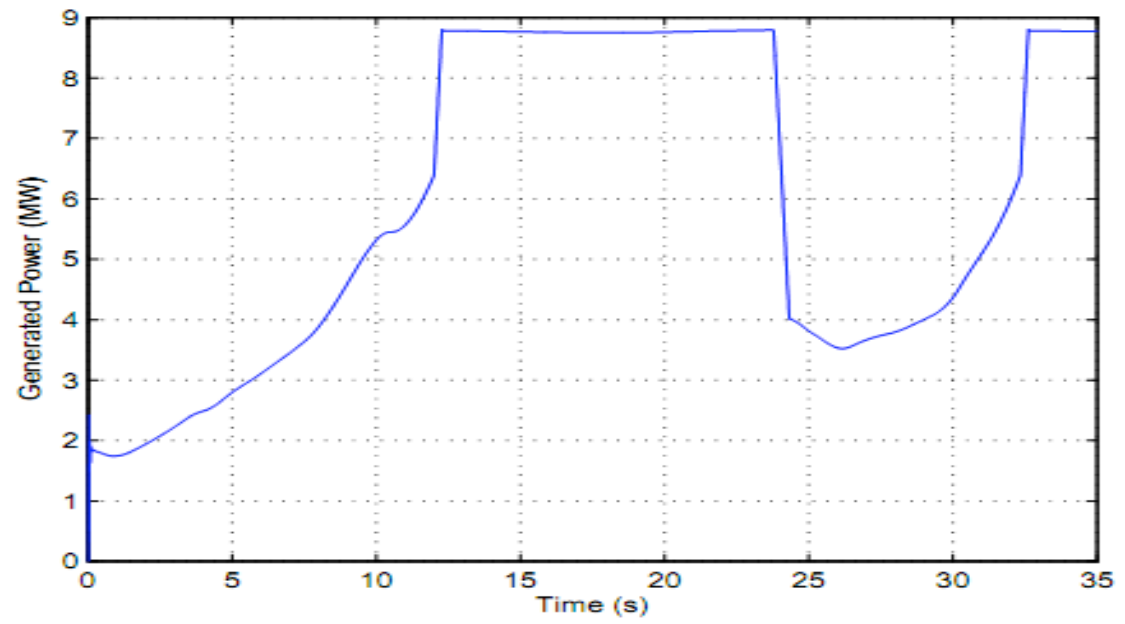

Figure 9: Generated Active Power (Source: Generated by the study).

The observation from Figure 9 showed that the generated active power, whose value is maximised by the proposed sliding mode control scheme, was maximum at the time 13.3s. The mechanical power of the turbine and therefore the generated active power should be limited by the pitch angle so as not to exceed the rated power of the system.
It was also identified that a significant amount of wind power can be integrated into the Kenyan grid without adverse operational effect. Assuming present day capital cost the result suggests that the installation of $9 \mathrm{MW}$ of wind power in Mokowe could be economical. 


\section{CONCLUSIONS AND RECOMMENDATIONS}

The results from this study show that:

- At $50 \mathrm{~m}$ above the ground, the wind speed at Mokowe site varies from $4 \mathrm{~m} / \mathrm{s}$ to about $8 \mathrm{~m} / \mathrm{s}$.

- The electrical active power generated is maximized using the proposed sliding mode control.

- $\quad$ The wind regime available at the proposed site matches the technical characteristics of the selected WTG - for optimum electrical power production from wind.

- The objectives of the study have been met.

The study makes the following recommendations:

A field survey should be done to validate the simulation results.

Socio-economic needs assessment of the community at Mokowe should be carried out.

Other good wind regime sites along the Indian Ocean shoreline in Mokowe should also be identified.

\section{ACKNOWLEDGEMENTS}

We thank Technical University of Mombasa for their valuable financial support to carry out this research project.

\section{REFERENCES}

[1] Gans F, Miller LM, Kleidon A. The problem of wind turbine a note on a common but flowed wind power estimation method. Earth System Dynamics 2010; 1: 103-14.

[2] Ministry of Energy, Kenya Electricity Access Investment Prospectus 2009-2014. Republic of Kenya, Nairobi 2009.

[3] Saulo MJ, Gaunt CT. Implication of national policy on electricity distribution system planning in Kenya. Proceeding of the $19^{\text {th }}$ South African Universities Power Engineering Conference, SAUPEC 2010; pp. 132-137.

[4] Nichita C, Luka D, Dayko B, Ceanga E. Large band simulation of wind speed for real time wind turbine simulators. Power Eng Rev IEEE 2002; 22(8): 63-65. http://dx.doi.org/10.1109/MPER.2002.4312482

[5] Bayem H, Phulpin Y, Desante, Bect J. Probabilistic computation of wind farm power generation based on wind turbine dynamic modeling. $10^{\text {th }}$ International Conference on Probabilistic Methods Applied to Power Systems-.PMAPS 2008; Porto Rico, 1-6.

[6] Billington R, Chen H, Ghajar R. Time series models for reliability evaluation of power systems including wind energy. Microelectronics Reliability 1996; 36(9): 1253-61. http://dx.doi.org/10.1016/0026-2714(95)00154-9

[7] Allerton T. Simulating the distribution and cross correlation of wind farm output, ESG164: Heriot-Watt University. The Knowledge Transfer Network for Industrial Mathematics, The international centre for mathematical sciences 2008 Report.

[8] Aksoy Fuat H, Toprak Aytek Z, Erdem Nal A. Stochastic generation of hourly wind data. El-Sevier - Renewable Energy 2004; 29(14): 2111-31. http://dx.doi.org/10.1016/j.renene.2004.03.011

[9] Kremers E, Viejo P. Simulations of energy system scenarios for regional planning decision making using agent based modeling. $11^{\text {th }}$ int. conf. on computers in urban planning and urban management. Hongkong, June 2009.

[10] Kremers E, Lewald L, Barambones. Gonzalez de Durana O. argent -based multi-scale wind generation model. Proceedings of the ninth IASTED European conference power and energy systems (Euro 2009) Palma de Mallorea Spain.

[11] Chedid Akiki R, Rahman S. A decision support technique for the design of the hybrid solar-wind power systems. IEEE Trans Energy Conversion 1998; 13(1): 76-83. http://dx.doi.org/10.1109/60.658207

[12] Fernando D, Bianchi, Harnan De Battista, Ricardo JM. Wind turbine control system. Advances in industrial control series Springer 2007.

[13] Akhamatov V. Variable speed wind turbines with Doubly-Fed Induction Generators. Wind Eng 2002; 26(2): 85-108. http://dx.doi.org/10.1260/030952402761699278

[14] Song YD, Dhinakaran, Bao XY. Variable speed control of speed turbines using non-linear and adaptive algorithms. $J$ Wind Eng Ind Aerodynamics 2000; 85: 293-308.

[15] Pena R, Clare JC, Asher GM. Doubly fed induction generator using back to back PWM converters and its application to variable speed wind-energy generation. Proc Inst Elect Eng 1996; 143(3): 231-41.

[16] Wei Q, Wei Z, Aller JM, Ronald GH. Wind speed estimation based Sensor less Output Maximization Control for Wind Turbine Driving a DFIG IEEE Trans. On Power Electronics 2008; 23(3): 1156-69.

[17] Herbert GM, Iniyan Sree-Valsan S, Rajapandian S. A review of wind energy technologies. Renewable Sustainable Energy Rev 2007; 11: 1117-45.

[18] Siegfried $H$. Grid integration of wind energy conversion systems John Wiley and Sons Ltd 1998 ISBN 0-471-97143X.

[19] Yazho Mullane L, Lightbody G, Yacamini. Modeling of the wind turbine with a Doubly Fed Induction Generator for Grid integration studies. IEEE Trans Energy Conver 1998; 13(1): 76-83.

http://dx.doi.org/10.1109/60.658207

[20] Novotny DW, Lipo TA. Vector control and Dynamic of AC drives Oxford, U.K. Oxford Univ. Press 2000.

[21] SimPowerSystems 5.Users Guide, the Maths Works. 